(2) Open Access Full Text Article

\title{
Assessment of the Effect of Vitiligo on Subfoveal Choroidal Thickness Using Spectral-Domain Optical Coherence Tomography
}

This article was published in the following Dove Press journal: Clinical Ophthalmology

\author{
Yousef Ahmed Fouad (D)' \\ Abdelrahman Gaber Salman' \\ Thanaa Helmy Mohamed (D) ' \\ Randa Hesham Ali Abdelgawad (iD) \\ Samah Ibraheem Hassen (iD ${ }^{2}$ \\ 'Department of Ophthalmology, Faculty \\ of Medicine, Ain Shams University, Cairo, \\ Egypt; ${ }^{2}$ Department of Dermatology, \\ Faculty of Medicine, Ain Shams \\ University, Cairo, Egypt
}

Background: Vitiligo is a common skin condition affecting $0.5-2 \%$ of the population. The exact etiology of the condition is unknown, but the result is autoimmune destruction of melanocytes. The eye is rich in melanocytes, especially in the retinal pigment epithelium and choroid. Little is known about the effect of vitiligo on the choroid of the eye.

Methods: We cross-sectionally examined 31 right eyes of 31 vitiligo patients and 32 right eyes of 32 age- and sex-matched controls for signs of vitiligo affection and then measured the subfoveal choroidal thickness (SFCT) using spectral-domain optical coherence tomography.

Results: There was a statistically significant difference between SFCT in the cases group and the control group (Mean \pm SD: $251.9 \pm 42.0 \mu \mathrm{m}$ and $296.8 \pm 46.4 \mu \mathrm{m}$, respectively, $\mathrm{p}=$ 0.0002). The thickness correlated negatively with age $(\mathrm{r}=-0.5)$ but did not correlate significantly with disease severity or duration $(\mathrm{r}=-0.201,-0.1781, \mathrm{p}=0.2783,0.3381$, respectively). Additional examination findings included iris and fundus hypopigmented spots, and peripapillary atrophy.

Conclusion: SFCT is reduced among patients with vitiligo. The clinical implications of such a finding should be studied further, and eye screening programs should be considered.

Keywords: vitiligo, OCT, optical coherence tomography, choroidal thickness

\section{Synopsis}

Subfoveal choroidal thickness is reduced in vitiligo patients which confirms the systemic nature of the disease for which the eye might be a screening window.

\section{Introduction}

Vitiligo is a common chronic depigmenting disorder affecting $0.5-2 \%$ of the general population. ${ }^{1}$ The exact pathogenesis that leads to selective loss of melanocytes remains to be understood but a combination of environmental and immune factors in a genetically predisposed individual is a probable explanation. ${ }^{2,3}$ The systemic nature of the disease has recently been in focus. ${ }^{4,5}$ Reports of melanocyte affection in other parts of the body in vitiligo patients have been accumulating in the literature. ${ }^{5}$

The eye is rich in melanocytes, mainly in the uveal tissue and in the retinal pigment epithelium (RPE), ${ }^{6}$ and thus has long been implicated as a target in the disease. ${ }^{7,8}$ Early reports could not utilize a modality except clinical examination (slit-lamp biomicroscopy
Correspondence: Yousef Ahmed Fouad Department of Ophthalmology, Faculty of Medicine, Ain Shams University, Ramses

Street, Cairo, Egypt

Tel +20 106378/237

Email yousef.a.fouad@gmail.com 
and fundoscopy) to examine the eyes of vitiligo patients. Nevertheless, multiple pigmentary and non-pigmentary anomalies had been early reported in such eyes, most prominently increased incidence of choroidal nevi, iris focal atrophy, hypopigmented spots in the fundus, and increased incidence of dry eye. $^{7-9}$ With the advent of imaging and electrophysiological modalities, closer dissection of eye anatomy and function in vitiligo patients has been possible. This resulted in various reports on RPE, retinal nerve fibers, choroid, and electrophysiological function in vitiligo patients. ${ }^{10-12}$

New Optical Coherence Tomography (OCT) machines have allowed the measurement of choroidal thickness. The choroid is the most vascular part of the eye and gives direct nutrition to the retina. ${ }^{6}$ Recent reports have emerged linking choroidal thickness, especially the subfoveal choroidal thickness (SFCT), with various ocular ${ }^{13,14}$ and systemic ${ }^{15,16}$ abnormalities. A single recent report has examined choroidal thickness in vitiligo patients and the results demonstrated a significant reduction in thickness in such patients with no relation to disease duration and with some correlation to disease severity. ${ }^{17}$

We set out to investigate SFCT in vitiligo patients in comparison to a control group, and any correlation it may have to disease severity and duration.

\section{Methods}

\section{Study Design and Setting}

This cross-sectional study was conducted in Ain Shams University Hospitals where patients were recruited from the vitiligo clinic at the department of Dermatology and examined in the department of Ophthalmology. The study spanned the period between January 2018 and July 2019. Age- and sexmatched healthy controls were also included in the study.

Patients were eligible for the study if they had an isolated dermatological diagnosis of cutaneous vitiligo. The exclusion criteria were variables that might confound with choroidal thickness measurements. Patients were excluded if they had a systemic condition reported or presumed to affect the choroid such as hypertension, diabetes, and atherosclerosis, or an ocular condition reported or presumed to affect the choroid such as previous ocular trauma or surgery, or high refractive error $(+6$ and -6 diopters as cycloplegic spherical equivalent). Patients with history of inflammatory eye conditions that could have been an attack of uveitis (e.g. Vogt-KoyanagiHarada (VKH), sympathetic ophthalmitis, or viral uveitis) were excluded from the study. Smokers and pregnant females were also excluded from the study.

\section{Study Procedures}

Patients presenting to the vitiligo clinic were asked for full history of their disease and the Vitiligo Area Scoring Index (VASI) was calculated as described in the literature $(\Sigma$ all body sites (hand units) $\mathrm{x}$ depigmentation). ${ }^{17}$

All study subjects underwent a full ophthalmological examination including corrected distance visual acuity (CDVA) measurement using a Snellen chart, slit-lamp biomicroscopy, intraocular pressure (IOP) measurement using Goldmann Applanation Tonometry, cycloplegic refraction, and fundus examination.

Patients were then examined using spectral domainOCT (Retinascan RS-3000 advance; NIDEK, Gamagori, Japan). Dilated eyes eligible for the study were subjected to choroidal mode imaging using line scans. Subfoveal choroidal thickness was then manually determined on static output images. Subfoveal choroidal thickness was measured as a perpendicular line extending from the hyperreflective RPE line in the foveal region to the line representing the sclero-choroidal interface. Measurements were determined by two independent investigators, and the mean measurement was obtained as the outcome. All measurements were taken during the daytime between 9 am and 12 am to avoid diurnal variation patterns of choroidal thickness.

\section{Ethical Considerations}

No identifying information was used in the study. Ethical approval was obtained from the ethical review committee, faculty of medicine, Ain Shams University, and the study followed the tenets of the declaration of Helsinki. Written informed consent was obtained from all participants.

\section{Statistical Analysis}

Data were revised and tabulated in an Excel sheet (Microsoft, United States), and were then exported to SPSS v25 (IBM, United States) for statistical analysis.

\section{Results}

The study included 31 right eyes of 31 cases with vitiligo in the study arm, and 32 right eyes of 32 age- and sex-matched healthy subjects in the control arm. The mean age of the cases was 38.8 years (SD: 13.6 years) and the mean age of the controls was 37.6 years (SD: 12.4 years). The female to male ratio was the same in both groups $(\mathrm{F}: \mathrm{M}=1.6: 1)$. 
The mean duration of vitiligo in the included cases was 5.6 years (SD: 5.5 years). All patients had non-segmental distribution of the vitiligo (the most prevalent form). The mean duration of treatment was 3.6 years (SD: 3.4 years), which was phototherapy in all patients. The mean VASI score among the cases was 28 (SD: 14.2), and 56.3\% $(\mathrm{n}=9)$ had periocular skin involvement, of which $22.2 \%(n=2)$ were unilateral.

Table 1 demonstrates the refractive, visual, and IOP data for both groups. A statistically significant difference $(p=0.0109)$ was found between cases and controls as regards CDVA. The differences between refraction (calculated as spherical equivalent values) and IOP measurements between both groups were not statistically significant $(\mathrm{p}=0.1131$ and $\mathrm{p}=0.9348$, respectively).

The major findings during slit-lamp examination and fundus microscopy are depicted in Table 2. About a quarter of the eyes of the cases $(n=8,25.8 \%)$ had focal iris atrophy ranging from a subtle transillumination defect and up to small atrophic patches. This was not noted among any of the control eyes. Regarding fundus examination, over a third of the eyes in the cases group $(\mathrm{n}=12,38.7 \%)$ had some form of RPE mottling ranging from fine granularity and up to blotches of contrasting shades, while only 2 eyes in the control group (6.25\%) had RPE mottling. Furthermore, 3 eyes in the cases group $(9.68 \%)$ had a well-defined hypopigmented patch in their fundus exam; this was not noted among any of the control eyes.

Figure 1 demonstrates a hypopigmented lesion discovered on fundus examination of one of the vitiligo cases in our study and a relatively thin SFCT in the same case.

The mean SFCT among cases was $251.9 \mu \mathrm{m}$ (SD: 42 $\mu \mathrm{m}$ ), while the mean SFCT among controls was $296.8 \mu \mathrm{m}$
(SD: $46.4 \mu \mathrm{m}$ ). The difference was statistically significant $(\mathrm{p}=0.0002)$.

Correlation between SFCT and different variables is demonstrated in Table 3. A strong negative correlation existed between SFCT and age $(r=-0.5013, p<0.0001)$. Insignificant weak negative correlations existed between SFCT and disease duration, treatment duration, VASI score, periocular skin involvement, spherical equivalent, and CDVA.

\section{Discussion}

In this work, we have examined the eyes of vitiligo patients and compared them to a group of age- and sexmatched controls, with a special focus on the SFCT. We found a statistically significant difference between the lower SFCT among cases and the higher SFCT among controls. We also recorded several previously described findings in eyes of vitiligo patients.

The lower SFCT in the cases is in line with the recent work by Demirkan et al, ${ }^{17}$ although the mean SFCT in their cases was lower than the mean SFCT in our studied cases ( $221 \mu \mathrm{m}$ and $252 \mu \mathrm{m}$, respectively); the same difference was found in our control groups. The different ethnicities of the study subjects in the two studies (Turkish population vs Egyptian population) may explain the difference in mean choroidal thickness measurements as ethnicity is reported to affect choroidal thickness. ${ }^{18}$

The decrease in SFCT in our study did not correlate with disease severity (determined by VASI score), disease duration, treatment duration, nor periocular skin involvement. This is consistent with some of the findings of Demirkan et al. ${ }^{17}$ However, in their work, VASI scores were found to be moderately, negatively, and significantly correlated to choroidal thickness. The mean VASI score of

Table I Refraction, Corrected Distance Visual Acuity, and Intraocular Pressures of Cases and Controls

\begin{tabular}{|c|c|c|c|c|}
\hline \multicolumn{2}{|l|}{ Variables } & \multirow{2}{*}{$\begin{array}{l}\text { Cases } \\
\mathbf{N}=3 \mathbf{I}\end{array}$} & \multirow{2}{*}{$\begin{array}{l}\text { Controls } \\
N=32\end{array}$} & \multirow[t]{2}{*}{ p-value } \\
\hline & & & & \\
\hline Spherical Equivalent (Diopter) & $\begin{array}{l}\text { Mean } \pm \text { SD } \\
\text { Range }\end{array}$ & $\begin{array}{l}-0.73 \pm 1.54 \\
-3.5-2\end{array}$ & $\begin{array}{l}-1.36 \pm 1.57 \\
-3.75-2\end{array}$ & 0.1131 \\
\hline CDVA (decimal format) & $\begin{array}{l}\text { Mean } \pm \text { SD } \\
\text { Range }\end{array}$ & $\begin{array}{l}0.85 \pm 0.19 \\
0.3-1\end{array}$ & $\begin{array}{l}0.95 \pm 0.1 \\
0.8-1\end{array}$ & $0.0109 *$ \\
\hline IOP (mmHg) & $\begin{array}{l}\text { Mean } \pm S D \\
\text { Range }\end{array}$ & $\begin{array}{l}15.68 \pm 2.44 \\
1 \mid-22\end{array}$ & $\begin{array}{l}15.63 \pm 2.39 \\
11-20\end{array}$ & 0.9348 \\
\hline
\end{tabular}

Note: *Statistically significant. 
Table 2 Major Slit-Lamp and Fundus Examination Findings in Cases and Controls

\begin{tabular}{|l|l|l|l|l|}
\hline \multicolumn{2}{|l|}{ Variables } & Cases & Controls & p-value \\
\cline { 3 - 5 } & $\mathbf{N}=\mathbf{3}$ I & $\mathbf{N}=\mathbf{3 2}$ & \\
\hline Slit Lamp N (\%) & $\begin{array}{l}\text { Focal Iris Atrophy } \\
\text { Cataract }\end{array}$ & $\begin{array}{l}8(25.8) \\
5(16.1)\end{array}$ & $\begin{array}{l}0(0) \\
4(12.5)\end{array}$ & $\begin{array}{l}0.0023^{*} \\
0.6854\end{array}$ \\
\hline Fundus N (\%) & RPE Mottling & $12(38.7)$ & $2(6.25)$ & $0.002 I^{*}$ \\
& Hypopigmented Lesion & $3(9.68)$ & $0(0)$ & 0.0736 \\
& Peripapillary Atrophy & $3(9.68)$ & $2(6.25)$ & 0.6174 \\
\hline
\end{tabular}

Note: *Statistically significant.

the patients examined in their study was not mentioned in their report and thus we cannot compare their sample to our cohort of patients. Nevertheless, our work supports the fact that periocular skin involvement in vitiligo patients is not a predictor of eye affection, a topic that has been studied with conflicting results in the past years. ${ }^{19-21}$

Our data demonstrate a significantly lower CDVA in vitiligo patients when compared to age- and sex-matched controls. We could find two studies with ophthalmic assessment of vitiligo patients that included visual acuity comparisons with controls, and in both studies, the results showed that the difference was not statistically significant. ${ }^{17,22}$ Furthermore, we correlated CDVA values with SFCT measurements and found a weak, albeit borderline statistically significant, correlation which could provide a possible explanation. Although this is a novel finding, the small sample size and the possibility of confounders dictate further assessments before arriving at any conclusions.

During the slit-lamp examination, almost a quarter of our patients $(25.8 \%, \mathrm{n}=8)$ had focal iris stromal atrophy. This high percentage is in contrast to previous low rates of iris involvement in vitiligo patients. ${ }^{9,10,23}$ However, genetic and ethnic differences may play a role. For example, Cowan et al have demonstrated that a statistically significant higher occurrence of iris atrophy occurs in white vitiligo patients than black ones, ${ }^{23}$ and Ayotunde et al have shown that a sample of black patients with vitiligo did not suffer any uveal pigmentary abnormality. ${ }^{24}$

Fundus examination of vitiligo patients in our study revealed RPE mottling in $38.7 \%$ of vitiligo cases $(n=12)$. This is in line with previous work that reported RPE changes in $35.7 \%,{ }^{9} 26.9 \%,{ }^{8} 27 \%,{ }^{7}$ and $22.2 \%{ }^{25}$ of the studied samples. Three of our patients $(9.7 \%)$ had a focal welldemarcated area of RPE atrophy giving a hypopigmented spot appearance (Figure 1). Similar lesions have been described in the literature, with reported rates of $4.5 \%$ and $6.5 \%$ in the studied vitiligo samples. ${ }^{10,25}$ None of our patients had evidence of choroidal nevi in their fundus examination. Reports on choroidal nevi in vitiligo patients have varied, with some studies on black populations reporting $0 \%$ incidence in the studied sample ${ }^{24}$ and others reporting up to $40 \%$ in a Jewish population. ${ }^{10}$

The IOP measurements in our studied sample did not significantly vary from those of the control group. This is consistent with other studies that report average IOP measurements in vitiligo patients when compared to controls $^{17,22}$ and that vitiligo in itself does not singnificantly increase the risk of glaucoma occurrence, neither does the use of periocular steroid creams. ${ }^{26}$

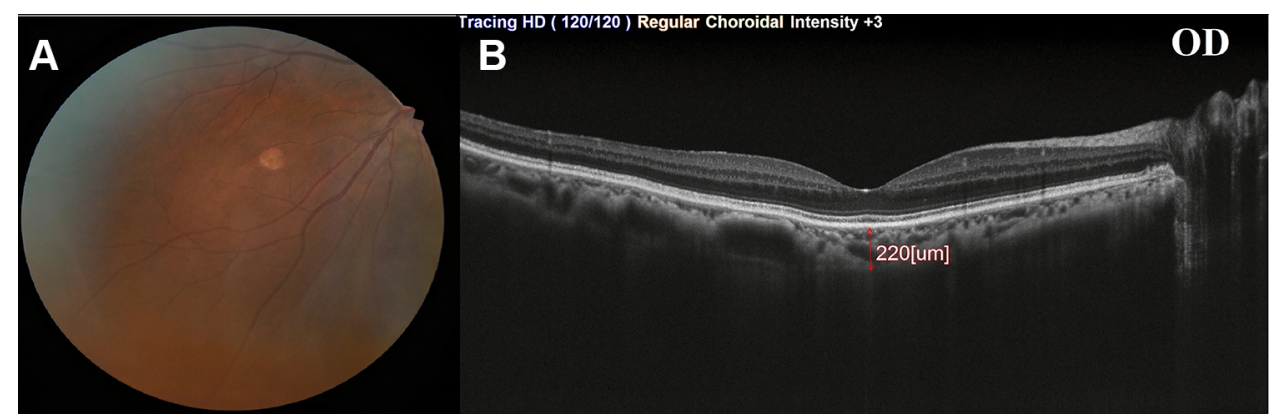

Figure I A 32-year-old female with two years duration of illness, (A) fundus photography revealing a hypopigmented lesion detected in the lower nasal quadrant of the right eye, and (B) SFCT measurement using SD-OCT in the right eye. 
Table 3 Correlation Between SFCT and Different Variables

\begin{tabular}{|l|l|l|l|}
\hline \multicolumn{2}{|l|}{ Variables } & $\mathbf{r}$ & p-value \\
\hline SFCT Cases & Disease Duration & $-0.178 \mathrm{I}$ & $0.338 \mathrm{I}$ \\
$(\mathrm{n}=3 \mathrm{I})$ & Treatment Duration & -0.1583 & 0.3959 \\
& VASI Score & -0.201 & 0.2783 \\
& Periocular Skin Involvement & $-0.0907^{\dagger}$ & 0.6274 \\
\hline SFCT Total & Age & -0.5013 & $<0.000 I^{*}$ \\
$(\mathrm{n}=63)$ & Sex & $0.2139^{\dagger}$ & 0.0922 \\
& Spherical Equivalent & $-0.086 \mathrm{I}$ & 0.5027 \\
& CDVA & 0.2464 & 0.0516 \\
\hline
\end{tabular}

Notes: ${ }^{\dagger}$ Point-Biserial correlation. *Statistically significant.

A limitation to our study is the small sample size. Another limitation is the manual measurements of SFCT, although we employed two different measurements by two independent investigators and averaged the numbers to get objective values. With the advent of new automated technologies with higher resolution power, more accurate measurements could be obtained. Furthermore, we only measured SFCT as the instrument employed in our study did not offer choroidal mapping; this would provide more accurate data on multiple-point measurements and could be a more useful comparative tool. Finally, the cross-sectional design of our work does not allow the establishment of a causal linkage or follow up for progression.

Finally, the literature is not clear when it comes to VKH disease and vitiligo. According to the revised diagnostic criteria for $\mathrm{VKH},{ }^{27}$ our patients only lack a part of one criterion to fall into the "incomplete VKH" category, which is the presence of history suggestive of prior active inflammation. We, thus, raise the question of whether our patients represent a form of aborted or subclinical VKH. Further molecular and biological studies are needed to understand the pathogenesis at play. ${ }^{28}$ Moreover, we raise the question of whether the classification of vitiligo should distinguish between those with isolated cutaneous involvement, and those with systemic involvement; it is not clear whether this latter group could be at a higher risk of developing progressive systemic pigmentary affection, and in that case, the eye would be the only direct window to detect and monitor such an involvement.

\section{Acknowledgments}

The authors would like to acknowledge the help of Professor Doctor Azza Mohamed Said, for her help with this work. The authors would also like to thank all contributing Dermatology and Ophthalmology personnel, who facilitated this work.

\section{Disclosure}

The authors report no funding and no conflicts of interest for this work.

\section{References}

1. Boniface K, Seneschal J, Picardo M, Taïeb A. Vitiligo: focus on clinical aspects, immunopathogenesis, and therapy. Clin Rev Allergy Immunol. 2018;54(1):52-67. doi:10.1007/s12016-017-8622-7

2. Picardo M, Dell'Anna ML, Ezzedine K, et al. Vitiligo. Nat Rev Dis Primers. 2015;1(1):15011. doi:10.1038/nrdp.2015.11

3. Rodrigues M, Ezzedine K, Hamzavi I, Pandya AG, Harris JE. New discoveries in the pathogenesis and classification of vitiligo. $J \mathrm{Am}$ Acad Dermatol. 2017;77(1):1-13. doi:10.1016/j.jaad.2016.10.048

4. Huggins RH, Janusz CA, Schwartz RA. Vitiligo: a sign of systemic disease. Indian J Dermatol Venereol Leprol. 2006;72(1):68-71. doi:10.4103/0378-6323.19730

5. Lotti T, D'Erme AM. Vitiligo as a systemic disease. Clin Dermatol. 2014;32(3):430-434. doi:10.1016/j.clindermatol.2013.11.011

6. Snell RS, Lemp MA. Clinical Anatomy of the Eye. John Wiley \& Sons; 2013.

7. Albert DM, Wagoner MD, Pruett RC, Nordlund JJ, Lerner AB. Vitiligo and disorders of the retinal pigment epithelium. $\mathrm{Br}$ J Ophthalmol. 1983;67(3):153-156. doi:10.1136/bjo.67.3.153

8. Wagoner MD, Albert DM, Lerner AB, Kirkwood J, Forget BM, Nordlund JJ. New observations on vitiligo and ocular disease. $A m$ $J$ Ophthalmol. 1983;96(1):16-26. doi:10.1016/0002-9394(83) 90450-6

9. Albert DM, Nordlund JJ, Lerner AB. Ocular abnormalities occurring with vitiligo. Ophthalmology. 1979;86(6):1145-1160. doi:10.1016/ S0161-6420(79)35413-6

10. Fleissig E, Pavlovksy M, Loewenstein A, et al. Prevalence of choroidal nevus and retinal pigment epithelial alterations in vitiligo patients. Graefes Arch Clin Exp Ophthalmol. 2018;256(5):927-933. doi:10.1007/s00417-018-3958-0

11. Ornek N, Onaran Z, Kocak M, Ornek K. Retinal nerve fiber layer thickness in vitiligo patients. J Res Med Sci. 2013;18(5):405-407.

12. Shoeibi N, Taheri AR, Nikandish M, Omidtabrizi A, Khosravi N. Electrophysiologic evaluation of retinal function in patients with psoriasis and vitiligo. Doc Ophthalmol. 2014;128(2):131-136. doi:10.1007/s10633-014-9425-2

13. Cheung CMG, Gan A, Yanagi Y, Wong TY, Spaide R. Association between choroidal thickness and drusen subtypes in age-related macular degeneration. Ophthalmol Retina. 2018;2(12):1196-1205. doi:10.1016/j.oret.2018.06.014

14. Mohamed DMF, Hassan NA, Osman AA, Osman MH. Subfoveal choroidal thickness in diabetic macular edema. Clin Ophthalmol. 2019;13:921-925. doi:10.2147/OPTH.S207376

15. Schuster AK, Leuschner A, Feretos C, et al. Choroidal thickness is associated with cardiovascular risk factors and cardiac health: the Gutenberg Health Study. Clin Res Cardiol. 2020;109(2):172-182.

16. Sızmaz S, Küçükerdönmez C, Pınarcı EY, Karalezli A, Canan H, Y1lmaz G. The effect of smoking on choroidal thickness measured by optical coherence tomography. $B r \quad J$ Ophthalmol. 2013;97 (5):601-604. doi:10.1136/bjophthalmol-2012-302393

17. Demirkan S, Onaran Z, Samav G, et al. Decreased choroidal thickness in vitiligo patients. BMC Ophthalmol. 2018;18(1):126. doi:10.1186/s12886-018-0796-0

18. Agarwal A, Invernizzi A, Jain S, et al. Choroidal thickness in patients diagnosed with human immunodeficiency virus infection: results from two populations of different ethnicities. Ocul Immunol Inflamm. 2019;27(4):560-566. doi:10.1080/09273948.2018.1439970

19. Erdur SK, Aydin R, Balevi A, Ozsutcu M, Kocabora MS. Dry eye assessment in patients with vitiligo. Cornea. 2018;37(4):412-415. doi:10.1097/ICO.0000000000001469 
20. Palamar M, Kiyat P, Ertam I, Yagci A. Evaluation of dry eye and meibomian gland dysfunction with meibography in vitiligo. Eye. 2017;31(7):1074-1077. doi:10.1038/eye.2017.38

21. Serin D, Buttanri IB, Parlak AH, Boran C, Tirak E. Impression cytology of the ocular surface and tear function in patients with periocular vitiligo. Eur J Ophthalmol. 2012;22(5):734-738. doi:10. 5301/ejo.5000099

22. Karadag R, Esmer O, Karadag AS, et al. Evaluation of ocular findings in patients with vitiligo. Int $J$ Dermatol. 2016;55(3):351-355. doi:10.1111/ijd.13031

23. Cowan CL, Halder RM, Grimes PE, Chakrabarti SG, Kenney JA. Ocular disturbances in vitiligo. J Am Acad Dermatol. 1986;15 (1):17-24. doi:10.1016/S0190-9622(86)70136-9

24. Ayotunde A, Olakunle G. Ophthalmic assessment in black patients with vitiligo. J Natl Med Assoc. 2005;97(2):286-287.

25. Bulbul Baskan E, Baykara M, Ercan I, Tunali S, Yucel A. Vitiligo and ocular findings: a study on possible associations. J Eur Acad Dermatol Venereol. 2006;20(7):829-833. doi:10.1111/j.14683083.2006.01655.x
26. Khurrum H, AlGhamdi KM, Osman E. Screening of glaucoma or cataract prevalence in vitiligo patients and its relationship with periorbital steroid use. J Cutan Med Surg. 2016;20(2):146-149. doi: $10.1177 / 1203475415615325$

27. Read RW, Holland GN, Rao NA, et al. Revised diagnostic criteria for Vogt-Koyanagi-Haradadisease: report of an international committee on nomenclature. Am J Ophthalmol. 2001;131(5):647-652. doi:10. 1016/S0002-9394(01)00925-4

28. Prignano F, Betts CM, Lotti T. Vogt-Koyanagi-Harada disease and vitiligo: where does the illness begin? J Electron Microsc. 2007;57 (1):25-31. doi:10.1093/jmicro/dfm036
Clinical Ophthalmology

\section{Publish your work in this journal}

Clinical Ophthalmology is an international, peer-reviewed journal covering all subspecialties within ophthalmology. Key topics include: Optometry; Visual science; Pharmacology and drug therapy in eye diseases; Basic Sciences; Primary and Secondary eye care; Patient Safety and Quality of Care Improvements. This journal is indexed on PubMed

Submit your manuscript here: https://www.dovepress.com/clinical-ophthalmology-journal

\section{Dovepress}

Central and CAS, and is the official journal of The Society of Clinical Ophthalmology (SCO). The manuscript management system is completely online and includes a very quick and fair peer-review system, which is all easy to use. Visit http://www.dovepress.com/ testimonials.php to read real quotes from published authors. 